\title{
CORRECTIONS
}

\section{Toxic epidermal necrolysis}

Kim To and colleagues, the authors of this Minerva photo item (BMJ 2013;346:f685, doi:10.1136/bmj.f685), wish to make the following statement: "After publication of our article, we received an email from the admitting dermatology team at the Queen Elizabeth Hospital Birmingham saying that discussions with the patient's family revealed that the patient had had an absence seizure while boiling a kettle the day before his admission and had suffered a burn as a direct consequence. They therefore felt that the clinical presentation was more in keeping with scalds than with toxic epidermal necrolysis. At the time of presentation this aspect of the patient's history was not picked up despite repeated history taking from various clinicians. The patient had stated that the lesions were not there when he went to bed the night before and they were noticed by him first thing in the morning. The patient was transferred to Queen Elizabeth Hospital with a provisional diagnosis of toxic epidermal necrolysis after consultation with the local consultant dermatologist. Unfortunately, no further communication was received on this patient from the admitting trust after the patient's discharge, and several attempts at obtaining a copy of the discharge report from his general practitioner proved unsuccessful. This is why the final amended diagnosis has only now come to our attention."

Cite this as: BMJ 2013;346:f1217

๑ BMJ Publishing Group Ltd 2013 